Document downloaded from:

http://hdl.handle.net/10251/162572

This paper must be cited as:

Lozano-Torres, B.; Blandez, JF.; Galiana, I.; García-Fernández, A.; Alfonso-Navarro, M.; Marcos Martínez, MD.; Orzáez, M.... (2020). Real-Time In Vivo Detection of Cellular Senescence through the Controlled Release of the NIR Fluorescent Dye Nile Blue. Angewandte Chemie International Edition. 59(35):15152-15156.

https://doi.org/10.1002/anie.202004142

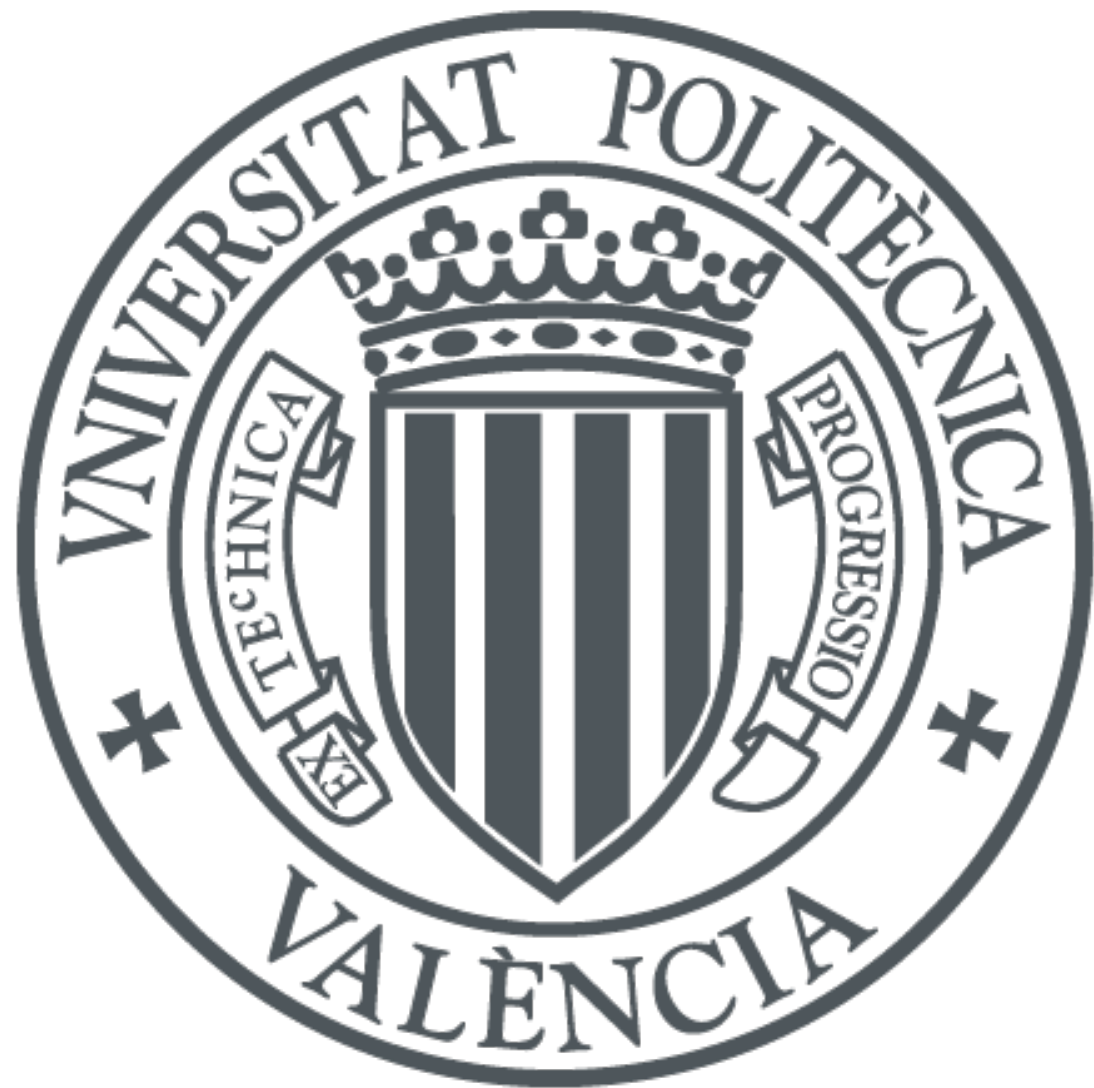

The final publication is available at

https://doi.org/10.1002/anie.202004142

Copyright John Wiley \& Sons

Additional Information

This is the peer reviewed version of the following article: B. Lozano-Torres, J. F. Blandez, I. Galiana, A. García-Fernández, M. Alfonso, M. D. Marcos, M. Orzáez, F. Sancenón, R. Martínez-Máñez, Angew. Chem. Int. Ed. 2020, 59, 15152., which has been published in final form at https://doi.org/10.1002/anie.202004142. This article may be used for noncommercial purposes in accordance with Wiley Terms and Conditions for Self-Archiving. 


\title{
Real time in vivo detection of cellular senescence through the controlled release of the NIR fluorescent dye Nile Blue
}

\author{
Beatriz Lozano-Torres, ${ }^{[a],[b],[c],[d], \dagger}$ Juan F. Blandez, ${ }^{[a],[b],[d], \dagger}$ Irene Galiana, ${ }^{\left[{ }^{[a],[b]}\right.}$ Alba García-Fernández, ${ }^{[c]}$ \\ María Alfonso, ${ }^{[a]}$ María D. Marcos, ${ }^{[a],[b],[c],[d]}$ Mar Orzáez, ${ }^{[b],[e]}$ Félix Sancenón, ${ }^{[a],[b],[c],[d] *}$ and Ramón \\ Martínez-Máñez ${ }^{[\mathrm{a}],[\mathrm{b}],[\mathrm{[c},[\mathrm{[d]}] \star}$
}

\begin{abstract}
In vivo optical detection of cellular senescence is accomplished by using mesoporous silica nanoparticles loaded with the NIR-FDA approved Nile Blue (NB) dye and capped with a galactohexasaccharide (S3). Emission at $672 \mathrm{~nm}$ of NB is highly quenched inside S3, yet a remarkable emission enhancement is observed upon cap hydrolysis in the presence of $\beta$-galactosidase and dye release. The efficacy of the probe to optically detect cellular senescence is tested in vitro in melanoma SK-Mel-103 and breast cancer $4 \mathrm{~T} 1$ cells and in vivo in palbociclib-treated BALB/cByJ mice bearing breast cancer tumor.
\end{abstract}

Cellular senescence is a stable state of cell cycle arrest necessary for maintaining the organism homeostasis. ${ }^{[1]}$ However the improper elimination of senescent cells, provokes local inflammation, tissue degeneration and contributes to aging. ${ }^{[2]}$ Today scientific evidence supports that accumulation of senescent cells is involved in the pathophysiology of many agerelated diseases ${ }^{[3]}$ and has boosted the concept that senescent cells is an attractive therapeutic target. ${ }^{[4,5]}$ Recent reports, using in vivo models, evidence that a wide variety of diseases can be ameliorated by the elimination of senescent cells. ${ }^{[6,7]}$

Characteristic signs of cellular senescence include changes in cell morphology ${ }^{[8]}$ the appareance of condensed nuclear chromatin foci, known as senescence-associated heterochromatic foci (SAHF). ${ }^{[9]}$ and the overexpression or activation of tumor supressor proteins such as p53, p16 ${ }^{\text {INK4a }}$ and p21 that contribute to cell cycle arrest. ${ }^{[10]}$ Moreover, one of the most widely used markers to detect celular senescence is the overexpression of lysosomal $\beta$-galactosidase, also referred to as senescence-associated $\quad \beta$-galactosidase $\quad(\mathrm{SA}-\beta-\mathrm{Gal}){ }^{[11]}$

[a] B. Lozano-Torres, Dr. J. F. Blandez, I. Galiana, Dr. M. Alfonso, Prof M. D. Marcos, Dr. F. Sancenón, Prof. R. Martínez-Máñez Instituto Interuniversitario de Investigación de Reconocimiento Molecular y Desarrollo Tecnológico (IDM), Universitat Politècnica de València, Universitat de València. Camino de Vera s/n, 46022Valencia, Spain. E-mail: rmaez@qim.upv.es

[b] B. Lozano-Torres, Dr. J. F. Blandez, I. Galiana, Prof. M. D. Marcos, Dr. M. Orzaez, Dr. F. Sancenón, Prof. R. Martínez-Máñez Unidad Mixta UPV-CIPF de Investigación en Mecanismos de Enfermedades y Nanomedicina, Universitat Politècnica de València, Centro de Investigación Príncipe Felipe, Valencia, Spain.

[c] B. Lozano-Torres, Alba García-Fernandez, Prof. M. D. Marcos, Dr. F. Sancenón, Prof. R. Martínez-Máñez CIBER de Bioingeniería, Biomateriales y Nanomedicina (CIBERBBN).

[d] B. Lozano-Torres, Dr. J. F. Blandez, Prof. M. D. Marcos, Dr. F. Sancenón, Prof. R. Martínez-Máñez

Unidad Mixta de Investigación en Nanomedicina y Sensores. Universitat Politècnica de València, IIS La Fe, Valencia, Spain.

[e] Dr. M. Orzaez

Centro de Investigación Príncipe Felipe. Eduardo Primo Yúfera, 3 Valencia 46012, Spain.

$+\quad$ Both authors contributed equally to this work
Measurement of SA- $\beta-G a l$ activity using chromo-fluorogenic probes has become popular as an easy and simple procedure to detect senescence. ${ }^{[12,13]}$ The use of molecularly imprinted nanopartilces has also been described recently for senescence detection. ${ }^{[14,15]}$ However, most of the actual probes are suitable for in vitro studies, whereas probes to detect cellular senescence in vivo in realistic senescence models are scarce. One general drawback of most of these probes is that, even in realistic senescence models, detection is only posible after the animal sacrifice. Consequently, the development of suitable methods for in vivo senescence detection remains an unresolved problem. ${ }^{[2]}$

Based on the above, we report herein the use of nanoparticles ${ }^{[16]}$ for in vivo detection of cellular senescence using a NIR fluorophore. The probe consists of galactohexasaccharide-capped mesoporous silica nanoparticles (MSNs) which are able to release their cargo in senescent cells due to the hydrolysis of the capping oligosaccharide by SA- $\beta$ Gal. ${ }^{[17]}$ We tested a number of fluorophores as cargo and finally selected Nile Blue (NB) due to its remarkable features as in vivo imaging agent. NB is an organic dye approved by the Food and Drug Administration (FDA) for human use ${ }^{[18]}$ and it exhibits near infrared (NIR) emission at $672 \mathrm{~nm} \cdot{ }^{[19,20]}$ Most importantly, NB is an aromatic planar fluorophore, which is highly quenched at high concentrations or in confined spaces as it forms non-emissive $\pi$ stacked aggregates. ${ }^{[21]}$

MSNs have been widely used as drug delivery systems due to their properties, such as biocompability and easy functionalization. ${ }^{[22]}$ In addition to MSNs, other carriers for cargo delivery such as liposomes, micelles, polymers, etc have also been used in recent years. ${ }^{[23]}$ In our case, MSNs were chosen as nanocarriers, due to their high loading capacity, allowing the NB dye to be entrapped at high concentration resulting in effective dye-dye $\pi$-stacking interactions and quenching. This compact packaging together with the gating capability exerted by the capping galactohexasaccharide (vide infra) would hardly be obtained using other nanocarriers. In fact, MSNs are well suited for the preparation of on-command delivery carriers by the functionalization of the outer surface with (bio)molecules that prevent payload release unless exposed to specific stimuli. ${ }^{[23]}$ Besides, in MSN the cargo is simply encapsulated, while in some other nanoparticles cargo molecules need to be covalently linked.

The prepared nanoparticles (i.e. S3 in Figure 1) are therefore poorly emissive, yet SA- $\beta$-Gal-induced hydrolysis of the capping hexagalacto-saccharide to give galactose residues, is expected to result in NB release, selectively inducing a marked NIR emission enhancement in senescent cells. Targeting of senescent cells in vitro with $\mathbf{S 3}$ is validated in SKMel-103 (human melanoma) and 4T1 (murine breast cancer) cell lines treated with palbociclib. Moreover, in vivo detection of cellular senescence is demonstrated in BALB/cByJ mice bearing 
breast cancer tumor treated with senescence-inducing chemotherapy.

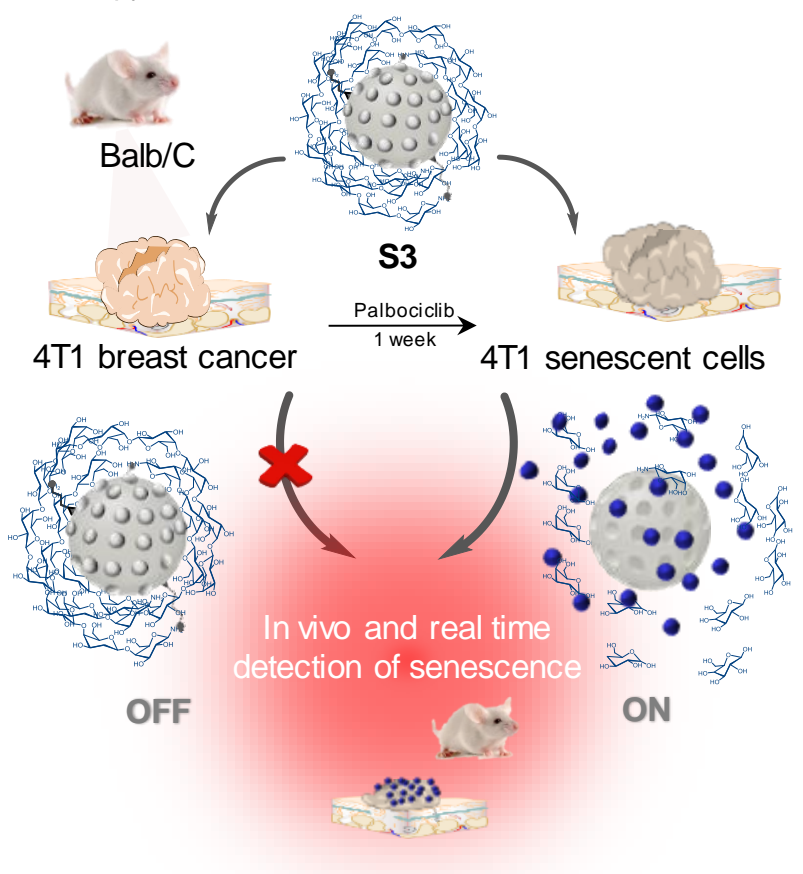

Figure 1. Representation of $\mathbf{S} 3$ activation in $B A L B / C B y J$ female mice orthotopically injected with $4 \mathrm{~T} 1$ cells to generate breast tumors. After tumor formation, mice were administered with palbociclib to generate senescence and treated with $\mathbf{S} 3$ achieving in vivo detection of cellular senescence.

S3 is easily prepared from mesoporous silica nanoparticles, ${ }^{[24]}$ which are loaded with NB, externally functionalized with APTES and finally capped with $\beta(1,4)$ hexagalacto-saccharide (Scheme S1).The mesoporous structure in $\mathbf{S 3}$ and the starting mesoporous silica material (SO) was clearly observed by HR-TEM (Figure 2a, b and S1a) and by powder X-ray diffraction (Figure S1b). S3 was also characterized by porosimetry (Figure S2a, b and Table S1), ATR (Figure S3) and DLS (Figure S4). Moreover, from dye delivery experiments and thermogravimetric studies, the content of NB in S3 was determined to be $0.45 \mathrm{mmol} \mathrm{g}^{-1}$ of solid (Figure S5).

Quenching of NB inside the pores of S3, was assessed. Free NB solutions presented much higher fluorescence than suspensions of $\mathbf{S 3}$, which showed negligible emission at equivalent NB concentrations (Figure 2c). Moreover, confocal images of S3 demonstrated that capped nanoparticles were poorly emissive (Figure S6). Quenching of NB at high concentrations was also studied in solution by monitoring the emission of the fluorophore at $666 \mathrm{~nm}\left(\lambda_{\mathrm{exc}}=635 \mathrm{~nm}\right)$ at different NB concentrations in water $(\mathrm{pH}=4.5)$-DMSO 99:1 v/v mixtures. Emission of NB solutions increased until a concentration of ca. $1.0 \times 10^{-4} \mathrm{M}$, whereas at higher concentrations the fluorescence decreased. In fact, NB concentrations higher than $10^{-3} \mathrm{M}$ are poorly emissive (Figure 2d). From the amount of NB loaded and the specific pore volume in S3 a molar concentration of the dye in the pores of ca. $0.49 \mathrm{M}$ was calculated which is in agreement with the low emission observed for $\mathbf{S 3}$ in Figure 2c.
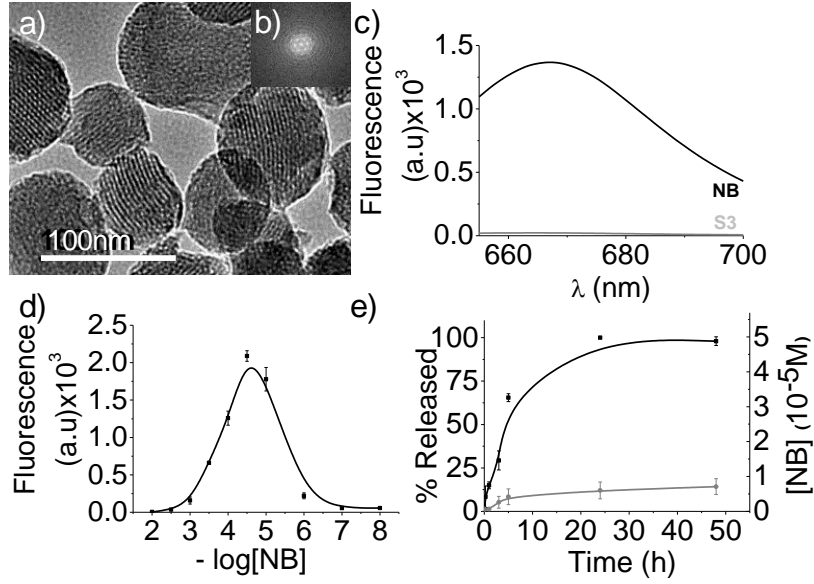

Figure 2. (a) HR-TEM images of S3, (b) TEM-EDX of S3. (c) Fluorescence of a NB solution $\left(1.81 \times 10^{-4} \mathrm{M}\right)$ and of $\mathrm{S3}$ suspensions at equivalent concentrations of the dye. (d) Emission intensity of NB solutions vs fluorophore concentration. (e) Release profile of S3 in the absence (grey line) and in the presence of $\beta$-Gal (black line). Experiments were carried out in water-DMSO 99:1 v/v mixtures at $\mathrm{pH} 4.5$. Error bars are expressed as $3 \sigma$

Delivery of NB from S3 was studied in the presence and in the absence of $\beta$-Gal enzyme (Figure 2e). S3 show a marked NB delivery in the presence of $\beta$-Gal of ca. $90 \%$ of the maximum dye released after $24 \mathrm{~h}$, which corresponded to $31.4 \%$ (5.69 $\mathrm{x}$ $10^{-5} \mathrm{M}$ ) of the dye entrapped (Figure S7). In contrast a low NB release in the absence of $\beta$-Gal was found. Release in the presence of $\beta$-Gal is due to the hydrolysis of glycosidic bonds in the capping galacto-saccharide which reduced steric crowding around the pores allowing NB delivery.

Specific targeting of senescent cells in vitro with S3 was demonstrated in SK-Mel-103 (human melanoma) and 4T1 (murine breast cancer) cells treated with $5 \mu \mathrm{M}$ palbociclib (a CDK4/6 inhibitor which suppresses DNA replication inducing cell cycle arrest) for two weeks to induce senescence. Senescence was confirmed by X-Gal staining (Figures $3 a, 3 e, 3 i$ and $3 m$ ). 

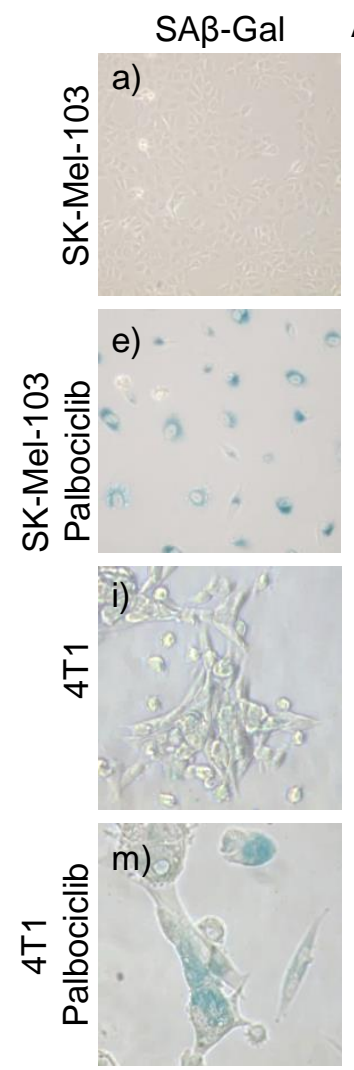
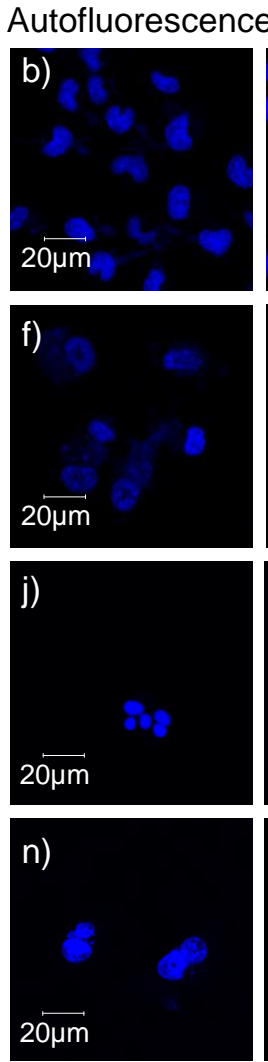
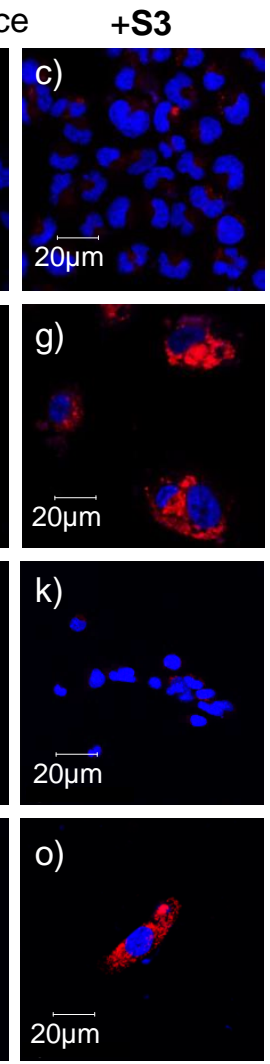

\section{+ Free NB}
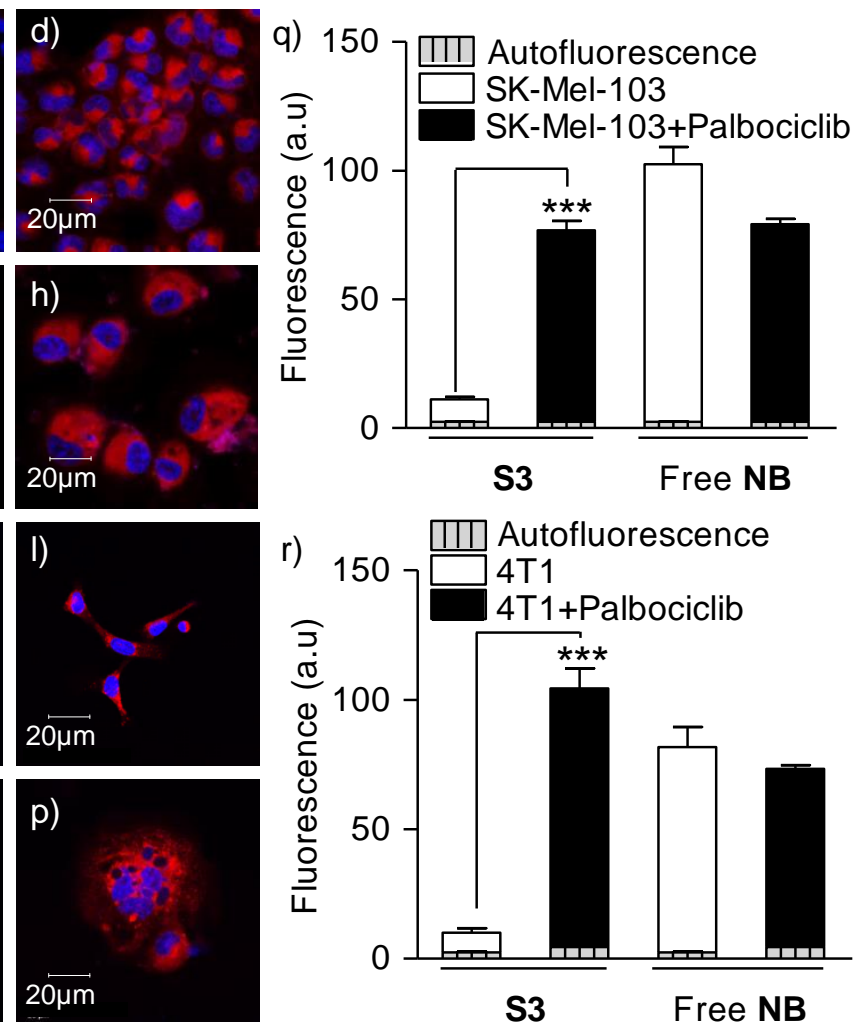

Figure 3. (a,e,i,m) X-Gal assay for detection of SA-B-Gal expression in (a) control and (e) senescent SK-Mel-103 cells and in (i) control $4 \mathrm{~T} 1$ and (m) senescent 4 T1 cells. (b,c) Confocal images of control SK-Mel-103 cells (b) in the absence or (c) in the presence of S3. (f,g) SK-Mel-103 cells treated with palbociclib (f) in the absence $(\mathrm{g})$ or in the presence of S3. (d,h) Confocal images of (d) control SK-Mel-103 cells or (h) SK-Mel-103 cells treated with palbociclib in the presence of equivalent doses of free NB. (j,k) Confocal images of control 4T1 cells (j) in the absence or (k) in the presence of S3. (n,o) 4T1 cells treated with palbociclib (n) in the absence (o) or in the presence of S3. (I,p) Confocal images of (I) control 4T1 cells or (p) 4T1 treated with palbociclib in the presence of equivalent doses of free NB. Cells were incubated with S3 $(7.8 \mu \mathrm{g} / \mathrm{ml})$ for $4.5 \mathrm{~h}$ in DMEM $(10 \% \mathrm{FBS})$ in $20 \% \mathrm{O}_{2}$ and $5 \% \mathrm{CO}_{2}$ at $37^{\circ} \mathrm{C}$, washed three times and stained with $\mathrm{Hoechst}$ $(1.5 \mathrm{ng} / \mathrm{ml})$ for $15 \mathrm{~min}$. Confocal images were acquired by using confocal microscope (Leica TCS SP8 AOBS). Representative images from repeated experiments $(\mathrm{n}=3)$ are shown. (q) Quantification of fluorescence emission ascribed to released NB in control and palbociclib-treated SK-Mel-103 cells incubated with S3 and quantification of fluorescence emission upon treatment with equivalent doses of free NB. Autofluorescence is the emission observed in SK-Mel-103 cells without treatment with S3 or free NB. (r) Quantification of fluorescence emission ascribed to released NB in control and palbociclib-treated 4T1 cells incubated with S3 and quantification of fluorescence emission upon treatment with equivalent doses of free NB. Autofluorescence is the emission observed in 4T1 cells without treatment with S3 or free NB. Error bars represent s.d.

Confocal microscopy studies of palbociclib-treated SKMel-103 and 4T1 cells, incubated with S3, revealed an intense fluorescent signal (Figure $3 \mathrm{~g}$ and 30 ), whereas non-senescent SK-Mel-103 and 4T1 cells treated with S3 presented weak fluorescence (Figure $3 \mathrm{c}$ and $3 \mathrm{k}$ ). Both control and senescent SK-Mel-103 and 4T1 cells showed also negligible background (Figures $3 \mathrm{~b}, 3 \mathrm{f}, 3 \mathrm{j}$ and $3 \mathrm{n}$ respectively). In addition, it was found that control and senescent cells treated with equivalent doses of free NB presented nearly the same fluorescence (Figures 3d, $3 \mathrm{~h}, 3 \mathrm{l}$ and $3 \mathrm{p}$, see also Figure S8). Quantification of fluorescence showed 7-fold emission enhancement in senescent SK-Mel-103 cells treated with S3 compared to controls (Figure $3 q$ ). For the 4T1 cell line, the emission enhancement of senescent cells tretaed with S3 when compared to control 4T1 cells was 10-fold. Results are indicative of $\mathbf{S} 3$ uptake and galacto-oligosacchadride hydrolysis by SA- $\beta-G a l$ in senescent cells, resulting in NB release.
Moreover it was found that S3 nanoparticles were not toxic for both control and senescent cells (Figure S9).

In vivo detection of celular senescence with S3 was validated in mice bearing breast tumors treated with senescence-inducing chemotherapy. For this purpose, BALB/cByJ female mice were orthotopically injected with 4T1 (mouse mammary carcinoma) cells $\left(0.5 \times 10^{6}\right.$ cell/mouse) to generate breast tumors. 

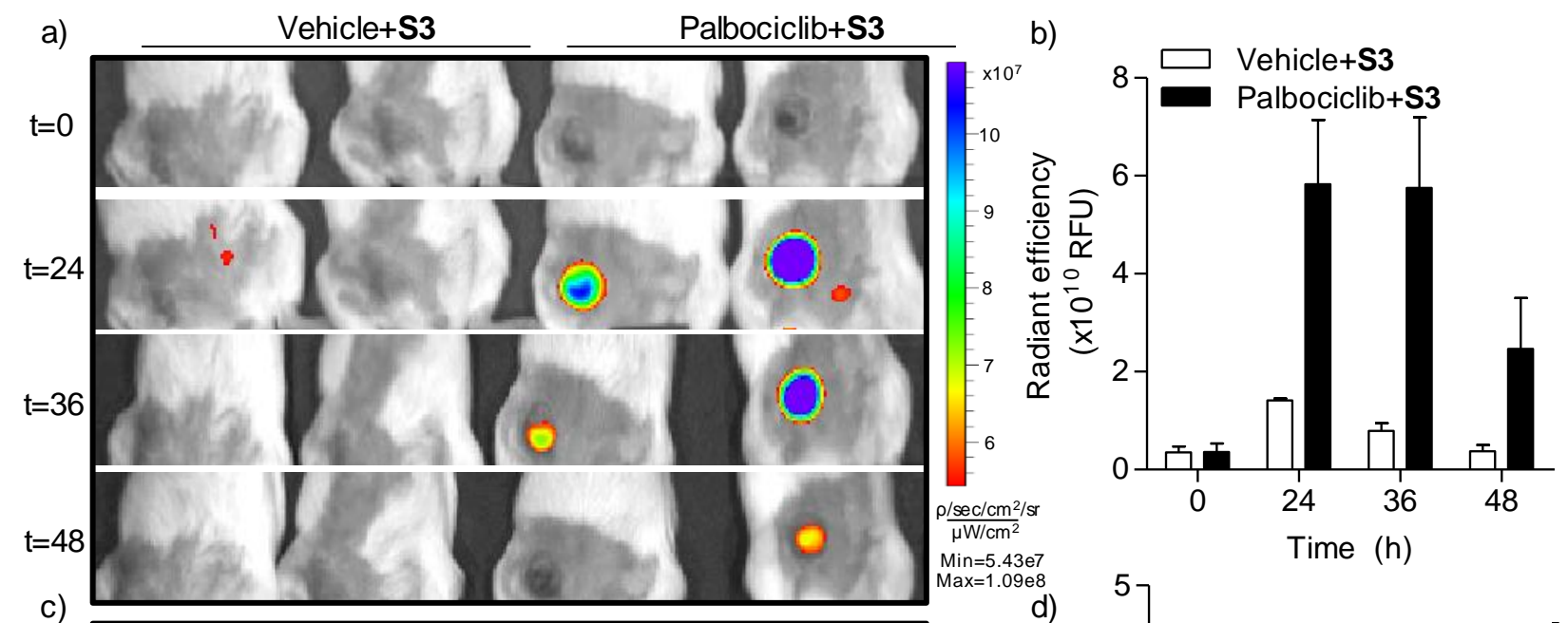

c)

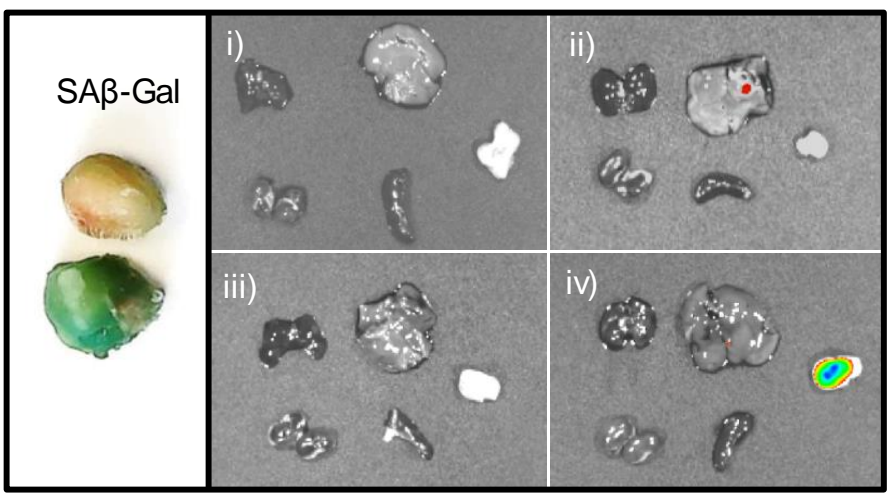

$\operatorname{Min}=5.43 \mathrm{e} 7$
$\operatorname{Max}=1.09 \mathrm{e} 8$
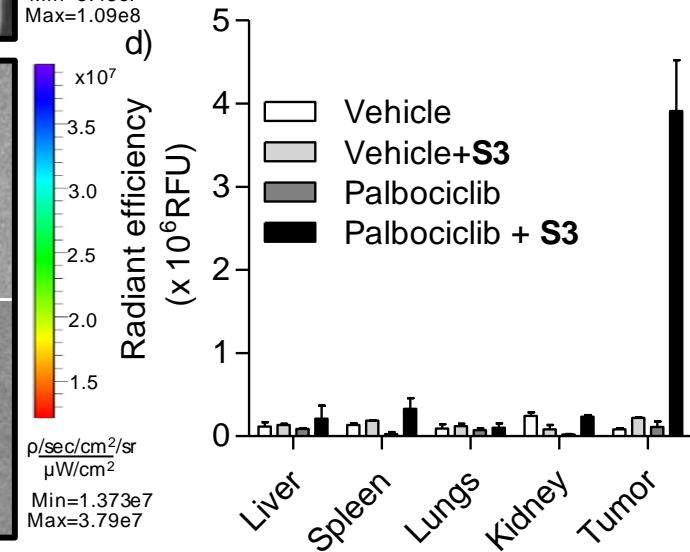

Figure 4. (a) IVIS images at different time points of BALB/cByJ female mice bearing 4T1 breast tumor. From left to right control mice treated with S3 (two mice from group B) and BALB/cByJ mice treated by oral gavage with palbociclib (senescent tumors) for 1 week and intravenously injected with S3 (two mice from group D). (b) Quantification of fluorescence emission intensity from tumor signals with time. Error bars represent s.d. (c) X-Gal assay for SA- $\beta$-Gal expression in tumors from control group A (up) and palbociclib-treated group C (bottom). (i,ii, iii,iv) IVIS images of organs and tumors from BALB/cByJ female mice bearing 4T1 breast tumor. From left to right and from top to bottom: lungs, liver, tumor, kidney and spleen. (i) Control mice (group A). (ii) Control mice treated with S3 (group B, $4 \mathrm{mg} / \mathrm{ml} 200 \mu \mathrm{l}$ ). (iii) BALB/cByJ female mice bearing 4T1 breast tumor treated oral gavage with palbociclib for 1 week (group C). (iv) Palbociclib-treated mice intravenously injected with S3 (group D, $4 \mathrm{mg} / \mathrm{ml} 200 \mu \mathrm{l}$ ). Mice were sacrificed $24 \mathrm{~h}$ post-treatment for these images. (d) Quantification of fluorescence emission from organs and tumors in i,ii,iii and iv images. Error bars represent s.d.

Mice were divided into four groups: (A) control individuals with 4T1 tumors; (B) control individuals with 4T1 tumors administered with S3; (C) mice only administered with palbociclib; and (D) individuals with 4T1 tumors treated with palbociclib and S3. Groups C and D were daily treated by oral gavage with palbociclib after tumor development to induce sensecence and arrest of tumor growth. Once completed 7 days of palbociclib treatment, S3 nanoparticles were intravenously administered to groups $B$ and $D$, and mice were monitored by an in vivo imaging system (IVIS) at different time points for 48 h. No autofluorescence was observed from control (A) and palbociclib (C) treated mice (Figure S10). Mice from groups A, B and C showed negligible fluorescence in the tumor area, while a strong fluorescent signal was observed for group D, which was administered both with palbociclib and S3 (Figure 4a). The peak of maximum fluorescence in mice treated with palbociclib and S3 (group D) was observed 24-36 $\mathrm{h}$ post-injection of the nanoparticles (Figure 4a), whereas a clear decrease in the fluorescence signal was found at $48 \mathrm{~h}$. Quantification of the relative values of radiance $\left(\mathrm{p} / \mathrm{s} / \mathrm{cm}^{2} / \mathrm{sr} \times 10^{10}\right)$ showed and enhancement of 4.3 fold at $24 \mathrm{~h}$ and 7.3 fold at $36 \mathrm{~h}$ in
palbociclib+S3 treated mice when compared to vehicle ones (Figure 4b).

Mice were euthanized and blood, lungs, liver, kidney, spleen and tumors were ex vivo analyzed. Senescence in tumors from mice treated with palbociclib was confirmed by $X$ Gal staining (Figure 4c) and reduced immunostaining of the Ki67 proliferation marker indicative of cell cycle arrest (Figure S11). IVIS images o excised organs and tumors from vehicle $(A)$ or palbociclib-treated mice $(C)$ did not show any fluorescence (Figures 4c, i) and iii)). Similarly, tumors from vehicle mice injected with S3 (B) did not show any noticeable fluorescent signal (Figure 4c, ii)). In contrast, strong emission (ca. 17.6 fold) was observed in tumors from mice treated with palbociclib and intravenously injected with S3 (Figure 4c, iv and Figure 4d). Biodistribution of nanoparticles was studied by determining silicon levels in various organs by inductively coupled plasma mass spectroscopy (ICP-MS) (Figure S12). Nanoparticles reach both senescent and non-senescent tumors at $24 \mathrm{~h}$ whereas levels of $\mathrm{Si}$ are significantly reduced $48 \mathrm{~h}$ post-injection, which is consistent with the patterns of fluorescence signal (vide ante). S3 also acumulated in spleen, lungs and kidney at $24 \mathrm{~h}$, whereas maxiumum silicon acumulation was found in spleen at 
48 h. Note that even though some mesoporous silica nanoparticles accumulate in liver, spleen or kidney, negligible fluorescence was detected in these organs $24 \mathrm{~h}$ post injection. This is due to the very low emission from the capped S3 (due to m-stacking NB interactions in the pores) and also indicates that nanoparticles remain capped in these organs which did not overexpress SA- $\beta$-Gal enzyme. Blood biochemistry and hematology analysis of different paremeters, such as albumin (ALB), bilirubin (BIL), alkaline phosphatase (AKP), glutamic pyruvic transaminase (GPT) and aspartate transaminase (GOT), showed no noticeable signs of organ damage and systemic inflammatory response after nanoparticles administration ( $B$ and D) when compared to $\mathbf{S} 3$ untreated (A and $C$ ) groups (Figure S13).

As summary, we describe here MSN loaded with NB dye and capped with a galacto-oligosaccharide for the in vivo detection of cellular senescence. S3 nanoparticles are poorly emissive due to $\pi$-stacking interactions of NB molecules densely packed onto the mesopores, yet NB is selectively released in senescent cells resulting in a marked emission enhancement. In vitro targeting of senescent cells with S3 was validated in SKMel-103 and 4T1 cells treated with palbociclib. A remarkable enhanced emission in palbociclib-treated SK-Mel-103 and 4T1 senescent cells was observed when incubated with S3 in comparison with control cells. S3 was validated in vivo in BALB/cByJ female mice orthotopically injected with $4 T 1$ cells to generate breast tumors and treated with palbociclib. In vivo IVIS images showed a remarkable emission enhancement ( 4.3 fold at $24 \mathrm{~h}$ and 7.3 fold at $36 \mathrm{~h}$ ) in tumors from mice treated with palbociclib and intravenously injected with S3, whereas negligible signal was found in mice only treated with $\mathbf{S 3}$ and in palbociclib-treated mice without $\mathbf{S 3}$ administration. In good accordance, ex vivo IVIS images showed that fluorescence ascribed to NB was only observed in senescent tumors (17.6fold enhancement) but not in control tumors or other organs. The performance in terms of selectivity and sensitivity makes $\mathbf{S} 3$ and efficient OFF-ON probe for the in vivo detection of senescence. We anticipate that this or similar probes able to detect cellular senescence in vivo will become essential tools to follow treatment response and efficacy of senotherapies in a wide range of aged-related diseases.

\section{Acknowledgements}

R.M thank financial support from the Spanish Government (RTI2018-100910-B-C41 and RTI2018-101599-B-C22 (MCUI/AEI/FEDER, UE)) and the Generalitat Valenciana (PROMETEO 2018/024). M.O. thanks the financial support from SAF2017-84689-R project and MINECO/AEI/FEDER, UE and the Generalitat Valenciana (PROMETEO/2019/065). B.L-T. is grateful to the Spanish Ministry of Economy for her PhD grant. I.G. thanks her contract from IDM. J. F.-B and M. A. thank the UPV for their postdoctoral fellowship.
[2] (a) B. Lozano-Torres, A. Estepa-Fernández, M. Rovira, M. Orzáez, M. Serrano, R. Martínez-Máñez, F. Sancenón, Nat. Rev. Chem. 2019, 3 , 426-441; (b) D. Muñoz-Espín, M. Serrano, Nat. Rev. Mol. Cell Biol. 2014, 15, 482-496.

[3] A. Hernandez-Segura, J. Nehme, M. Demaria, Trends Cell Biol. 2018 28, 436-453.

[4] D. J. Baker, B. G. Childs, M. Durik, M. E. Wijers, C. J. Sieben, J.A Zhong, R. Saltness, K. B. Jeganathan, G. C. Verzosa, A. Pezeshki, K Khazaie, J. D. Miller, J. M. van Deursen, Nature 2016, 530, 184-189.

[5] A. Soto-Gamez, M. Demaria, M. Drug Discov. Today 2017, 22, 786795.

[6] J. L. Kirkland, T. Tchkonia, Y. Zhu, L. J. Niedernhofer, P. D. Robbins, J. Am. Geriatr. Soc. 2017, 65, 2297-2301.

[7] L. J. Niedernhofer, P. D. Robbins, Nat. Rev. Drug Discov. 2018, 17, 377-377.

[8] L. Hayflick, P. S. Moorhead, Exp. Cell Res. 1961, 25, 585-621.

[9] R. Zhang, P. D. Adams, Cell Cycle 2007, 6, 784-789.

[10] J. Campisi, Cell 2005, 120, 513-522.

[11] G. P. Dimri, X. Lee, G. Basile, M. Acosta, G. Scott, C. Roskelley, E. E. Medrano, M. Linskens, I. Rubeli, O. Pereira-Smith, Proc. Natl. Acad. Sci. U.S.A. 1995, 92, 9363-9367.

[12] B. Lozano-Torres, I. Galiana, M. Rovira, E. Garrido, S. Chaib, A Bernardos, D. Muñoz-Espín, M. Serrano, R. Martínez-Máñez, F. Sancenón, J. Am. Chem. Soc. 2017, 139, 8808-8811.

[13] D. Asanuma, M. Sakabe, M. Kamiya, K. Yamamoto, J. Hiratake, M. Ogawa, N. Kosaka, P. L: Choyke, T. Nagano, H. Kobayashi, Y. Urano, Nat. Commun. 2015, 6, 6463.

[14] D. Muñoz-Espín, Transl. Med. Aging 2019, 3, 1-5.

[15] A. E. Ekpenyong-Akiba, F. Canfarotta, H. B. Abd, M. Poblocka, M. Casulleras, L. Castilla-Vallmanya, G. Kocsis-Fodor, M. E. Kelly, J. Janus, M. Althubiti, E. Piletska, S. Piletskyc, S. Macip, Nanoscale Horiz. 2019, 4, 757-768.

[16] (a) S. Alberti, G. Soler-Illia, O. Azzaroni, Chem. Commun. 2015, 51, 6050-6075; (b) C. de la Torre, I. Casanova, G. Acosta, C. Coll, M.J. Moreno, F. Albericio, E. Aznar, R. Mangues, M. Royo, F. Sancenón, R. Martínez-Máñez, Adv. Funct. Mater.2015, 25, 687-695.

[17] (a) A. Bernardos, E. Aznar, M.D. Marcos, R. Martínez-Máñez, F. Sancenón, J. Soto, J.M. Barat, P. Amorós, Angew. Chem. Int. Ed. 2009 48, 5884-5887; (b) A. Agostini, L. Mondragón, A. Bernardos, R. Martínez-Máñez, M.D: Marcos, F. Sancenón, J. Soto, A. Costero, C Manguan-García, R. Perona, M. Moreno-Torres, R. Aparicio-Sanchís, J.R. Murguía, Angew. Chem. Int. Ed. 2012, 51, 10556-10560; (c) D. Muñoz-Espín, M. Rovira, I. Galiana, C. Giménez, B. Lozano-Torres, M Paez-Ribes, S. Llanos, S. Chaib, M. Muñoz-Martín, A. C. Ucero, G Garaulet, F. Mulero, S. G. Dann, T. Van Arsdale, D. J. Shields, A Bernardos, J. R. Murguía, R. Martínez-Máñez, M. Serrano, EMBO Mol. Med. 2018, e9355.

[18] J. Mérian, J. Gravier, F. Navarro, I. Texier, Molecules 2012, 17, 5564 5591.

[19] X. Zhang, S. Bloch, W. Akers, S. Achilefu, Curr Prot. Cytom. 2012, 60, 12.27.1-12.27.20

[20] W. Fu, C. Yan, Z. Guo, J. Zhang, H. Zhang, H. Tian, W. -H. Zhu, J. Am. Chem. Soc. 2019, 141, 3171-3177.

[21] O. V. Ovchinnikov, A. V. Evtukhova, T. S. Kondratenko, M. S. Smirnov V. Y. Khokhlov, O. V. Erina, Vib. Spectrosc. 2016, 86, 181-189.

[22] (a) E. Aznar, M. Oroval, J. R. Murgía, R. Martínez-Máñez, F. Sancenón, Chem. Rev. 2016, 116, 561-718; (b) A. Llopis-Lorente, B. LozanoTorres, A. Bernardos, R. Martínez-Máñez, F. Sancenón, J. Mater Chem. B 2017, 5, 3069-3083; (c) A. García-Fernández, E. Aznar, R. Martínez-Máñez, F. Sancenón, Small 2020, 16, 1902242.

[23] (a) V. Kozlovskaya, B. Xue, E. Kharlampieva, Macromolecules 2016, 49 8373-8386; (b) D. K. Mishra, R. Shandilya, P. K. Mishra, Nanomedicine 2018, 14, 2023-2050; (c) F. Seidi, R. Jenjof, T. Phakkeeree, D. Crespy, J. Control. Release 2018, 284, 188-212; (d) W. Chen, S. Zhou, L. Ge, W. Wu, X Jiang, Biomacromolecules 2018, 19, 1732-1745; (e) M. VazquezGonzalez, I. Willner, Langmuir 2018, 34, 14692-14710; (f) R. M. Farid, N. A. H. A. Youssef, A. A. Kassem, Curr. Pharm. Des. 2017, 23, 66136629; (g) D. Lombardo, P. Calandra, D. Barreca, S. Magazu, M. A Kiselev, Nanomaterials 2016, 6, 125/1-125/26; (h) A. Bansal, Y. Zhang Acc. Chem. Res. 2014, 47, 3052-3060; (i) N. Kamaly, B. Yameen, J. Wu, O. C. Farokhzad, Chem. Rev. 2016, 116, 2602-2663.

[24] B. G. Trewyn, I. I. Slowing, S. Giri, H. -T. Chen, V. S. -Y. Lin, Acc. Chem. Res. 2007, 40, 846-853.

Keywords: senescence $\cdot$ mesoporous nanoparticles $\cdot$ Nile Blue - NIR • in vivo detection

[1] S. He, N. E. Sharpless, Cell 2017, 169, 1000-1011. 
In vivo detection of cellular senescence using mesoporous silica nanoparticles loaded with Nile Blue and capped with a galactohexasaccharide. Fluorescence dye emission is quenched inside nanoparticles, yet a remarkable fluorescence is observed upon cap hydrolysis by $\beta$-galactosidase. The probe is able to detect cellular senescence in vitro in SK-Mel-103 and 4T1 cells and in in vivo palbociclib-treated BALB/cByJ mice bearing breast tumors.

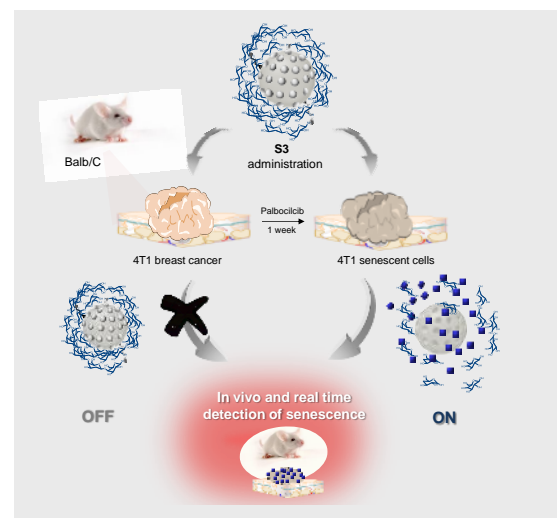

Beatriz Lozano-Torres, Juan F. Blandez, Irene Galiana, María Alfonso, María D. Marcos, Mar Orzaez, Félix Sancenón, * Ramón Martínez-Máñez*.

Page No. - Page No.

Real time in vivo detection of cellular senescence through the controlled release of the NIR fluorescent dye Nile Blue 